\title{
KAJIAN KOMPOSISI SERANGGA POLINATOR TANAMAN APEL (Malus sylvestris Mill) DI DESA PONCOKUSUMO KABUPATEN MALANG
}

\author{
Frank Leonardo Apituley ${ }^{(1)}$, Amin Setyo Leksono ${ }^{(2)}$, Bagyo Yanuwiadi ${ }^{(3)}$ \\ ${ }^{1}$ Program Studi Pengelolaan Sumberdaya Lingkungan dan Pembangunan, \\ Program Pasca Sarjana Universitas Brawijaya, Malang \\ ${ }^{2,3}$ Pasca Sarjana Universitas Brawijaya, Malang \\ e-mail : frapituley@gmail.com
}

\begin{abstract}
Abstrak
Pohon apel merupakan salah satu jenis pohon yang tidak dapat melakukan penyerbukan sendiri. Bunga apel tergantung pada serangga penyerbuk atau serangga polinator. Penelitian ini bertujuan untuk mengetahui komposisi serangga kanopi yang berpotensi sebagai polinator bunga apel dan menganalisis pola kunjungannya. Pengamatan serangga dilakukan secara visual. Pengukuran faktor lingkungan (suhu, kelembaban, dan cahaya). Analisis data struktur komunitas serangga pada saat musim berbunga dan berbuah didapatkan dari nilai penting dan diversitas (Indeks Shannon Wienner). Pola kunjungan dan komposisi serangga polinator dilakukan dengan membandingkan saat musim berbunga dan musim berbuah. Parameter yang dibandingkan diversitas, kelimpahan dan komposisi. Diversitas dan dan kelimpahan dibandingkan dengan uji anova, sedangkan komposisi dibandingkan dengan IBC (Indeks Bray Curtis). Pola kunjungan harian serangga polinator bunga apel dianalisis dengan membandingkan rata-rata kunjungan pada periode I, II, III, $I V$, dan V. Serangga polinator yang dikoleksi pada perkebunan apel musim bunga lebih tinggi yakni (363 individu) dari pada musim buah (151 individu). Nilai indeks keanekaragaman serangga polinator pada saat musim berbunga lebih tinggi $(2,08)$ dibandingkan musim buah (1,27). Kelimpahan serangga polinator antara musim bunga dan buah signifikan $P<0,001$. Kesamaan serangga polinator antara musim bunga dan buah denga indeks Bray Curtis sebesar 0,76 untuk musim bunga (AC, yaitu jam 07.0008.15 dengan 12.00-13.15) dan 0,74 untuk musim buah (AB, yaitu jam 07.00-08.15 dengan 09.00-10.15). Analisis faktor lingkungan suhu, kelembaban, dan intensitas cahaya terhadap kelimpahan serangga polinator didapatkan korelasi yang positif dengan nilai $R$-square yakni 43,2\%.

Kata Kunci : Struktur komunitas, Komposisi serangga polinator, Faktor abiotik.
\end{abstract}

\section{Pendahuluan}

Pohon apel merupakan jenis yang tidak bisa melakukan penyerbukan sendiri. Bunga apel tergantung pada serangga ka-nopi yang berperan sebagai polinator. Kua-litas buah apel sangat ditentukan dari jum-lah kunjungan dan penyerbukan yang di-lakukan oleh polinator (Kevan \& Phillips, 2001). Serangga penyerbuk secara umum me-ngunjungi bunga karena adanya faktor pe-narik yaitu bentuk bunga, warna bunga, serbuk sari dan nektar (sebagai penarik pri-mer) dan aroma (sebagai penarik sekun-der) serta dipengaruhi juga oleh faktor lingkungan. Faktor lingkungan yang mem-pengaruhi diantaranya adalah suhu dan ke-lembaban lingkungan, intensitas cahaya, serta kecepatan angin. Umumnya kecepa-tan angin mempengaruhi aktivitas terbang pada beberapa serangga. Lebih dari $80 \%$ spesies tanaman tergantung oleh serangga untuk membawa serbuksari dari bunga sa-tu ke bunga lain (Raju \& Ezradanam 2002; Faheem et al., 2004).

Kehadiran serangga pada tumbuh-an dapat membantu proses penyerbukan silang dan dapat meningkatkan hasil buah dan biji. Keuntungan penyerbukan silang pada tanaman adalah meningkatkan varia-bilitas keturunannya (Barth, 1991), me-ningkatkan kualitas dan kuantitas buah dan biji yang terbentuk (Kearns \& Inouye, 1997). Peranan serangga dalam penyer-bukan tumbuhan telah banyak dilaporkan. Pada tanaman apel (Malus sylvestris Mill) di Jepang, lebah Osmia cornifrons sebagai pe-nyerbuk, lebah Bombus terrestris dan Apis mellifera merupakan penyerbuk se-bagian besar tanaman pertanian (Amano et al., 2000). 
Peran polinator dalam penyerbu-kan dalam sebuah sistem pertanian saat ini menjadi terabaikan. Bahkan perencanaan pertanian modern lebih cenderung meni-tikberatkan pada penggunaan nutrisi tam-bahan dan pengendalian hama untuk menghasilkan produk yang diinginkan (Eka, 2006). Dampak pemakaian pestisida dan sistem pengelolaan pertanian yang ti-dak ramah lingkungan juga dapat mem-pengaruhi serangga kanopi. Perubahan ko-munitas serangga telah diketahui dapat memberikan dampak yang signifikan terhadap produksi apel. Penurunan kelimpah-an terutama pada kelompok serangga pe-nyerbuk (polinator) dapat mengurangi ku-alitas dan kuantitas produksi apel dan ko-muditas pertanian lain (Kevan \& Phillips, 2001). Hal ini disebabkan karena banyak seranga non target yang terkena pengaruh sehingga mengalami penurunan kelimpah-an dan diversitas.

Desa Poncokusumo merupakan salah satu daerah sentra perkebunan apel di wilayah Malang Jawa Timur yang cukup produktif dan potensial dikembangkan se-bagai daerah agrowisata. Beberapa tahun terakhir terjadi penurunan produksi apel, terkait dengan masalah sistem pengolahan tanah. Survei yang telah dilakukan menun-jukkan adanya sistem pertanian intensif yang sangat tergantung pada bahan-bahan sintetik. Sistem pengelolaan lahan meru-pakan faktor kunci dalam kelestarian serangga kanopi yang berperan sebagai poli-nator oleh karena itu perlu dilakukan in-ventarisasi jenis-jenis serangga kanopi, pe-ranan masingmasing terhadap kualitas lahan kebun apel, serta informasi menge-nai jenis-jenis serangga yang berperan se-bagai polinator. Dengan demikian maka masyarakat dapat melakukan tindakan konservasi untuk melestarikan jenisjenis tersebut.

\section{Bahan dan Cara Kerja}

Tempat. Perkebunan Apel di Dusun

Drigu Desa Poncokusumo, Kecamatan Poncokusumo Kabupaten Malang Jawa Timur. Lokasi pengambilan sampel adalah kebun apel seluas kurang lebih $2000 \mathrm{~m}^{2}$.

Pengambilan Sampel. Jenis penelitian yang digunakan dalam pengamatan serangga adalah penelitian deskriptif observasional, dengan menggunakan rancangan blok. Pengamatan serangga polinator diamati secara visual. Pengamatan disetiap lokasi dilakukan pada lima pohon apel, saat musim berbuah dan musim berbuah. Pada masing-masing lokasi pengamatan dilakukan sebanyak lima kali pada hari yang berbeda. Disetiap titik pengamatan dilakukan selama 15 menit setiap periode dengan periode pengamatan setiap hari sebanyak 4 kali (pagi dua kali yaitu jam 07.0008.15 , 09.00-10.15; siang pada jam 12.0013.15; dan sore hari jam 15.00-16.15) (Frei \& Manhart, 1992 dalam Erna, 2011). Serangga yang diamati di identifikasi sampai pada tingkat famili.

Analisis. Keanekaragaman pada setiap lokasi dihitung dengan Indeks Shannon Winner. Sedangkan kesamaan spesies menggunakan Indeks Bray Curtis (Magguran, 1998) . Variasi harian dan musiman struktur komunitas serangga yang berpotensi sebagai polinator bunga apel dilakukan dengan membandingkan pada saat musim bunga dan buah. Parameter yang dibandingkan kelimpahan dan diversitas. Kelimpahan dan diversitas dianalisis dengan uji anova, sedangkan komposisi dibandingkan dengan IBC (Indeks Bray Curtis). Pola kunjungan harian serangga polinator dianalisis dengan membandingkan rata-rata kunjungan periode $1,2,3,4$, dan 5 , kemudian dianalisis dengan uji anova.

\section{Hasil dan Pembahasan \\ Struktur Komunitas Serangga Pada Kebun Apel}

Total serangga yang dikoleksi pada saat musim berbunga dan berbuah adalah sebesar 2938 individu, terdiri dari 7 ordo dengan 35 famili. Ordo serangga dengan jumlah individu terbesar adalah Diptera 1618 individu, Hymenoptera 882 individu, Homoptera 143 individu, Coleoptera 141 individu, Hemiptera 100 individu, Lepidoptera 51 individu, dan Dermaptera 3 individu.

Kelimpahan serangga saat musim berbunga dan berbuah memiliki jumlah yang berbeda. Kelimpahan serangga saat berbunga lebih tinggi yaitu 1650 individu terdiri atas 7 ordo, 35 famili dimana kelimpahan serangga terbanyak dari famili Culicidae 211 individu, famili Dolichopodidae 189 individu, dan Pompilidae 182 individu, sedangkan saat berbuah kelimpahan serangga 1288 individu terdiri atas 6 ordo, 21 famili dimana kelimpahan serangga terbanyak diperoleh Dolichopodidae 176 individu, Pompilidae 174 individu, dan Chloropidae 132 individu (Tabel 1). Perbedaan jumlah famili pada musim bunga 
dan buah dipengaruhi oleh beberapa faktor, termasuk ketersediaan makanan dan tempat tinggal (Jumar, 2000). Hal ini selaras dengan hasil penelitian yang menunjukkan bahwa jenis serangga yang ditemukan pada saat pengamatan cukup beragam. Keberadaan serangga baik itu musuh alami, hama dan penyerbuk diduga dipengaruhi oleh ketersediaan makanan dan tempat tinggal yang berada di sekitar Tabel 1. Kelimpahan Serangga Pada Lokasi Perkebunan Apel

\begin{tabular}{|c|c|c|c|c|c|c|}
\hline \multirow{2}{*}{ No. } & \multirow{2}{*}{ Ordo } & \multirow{2}{*}{ Familli } & \multicolumn{2}{|c|}{ Musim } & \multirow{2}{*}{ Jumlah } & \multirow{2}{*}{$(\%)$} \\
\hline & & & Berbunga & Berbuah & & \\
\hline 1. & Diptera & Dolichopodidae & 189 & 176 & 365 & 12.42 \\
\hline 2. & Hymenoptera & Pompilidae & 182 & 174 & 356 & 12.12 \\
\hline 3. & Diptera & Culicidae & 211 & 127 & 338 & 11.50 \\
\hline 4. & Diptera & Chloropidae & 120 & 132 & 252 & 8.58 \\
\hline 5. & Hymenoptera & Ichneumonidae & 85 & 119 & 204 & 6.94 \\
\hline 6. & Diptera & Simuliidae & 105 & 98 & 203 & 6.91 \\
\hline 7. & Hymenoptera & Formicidae & 74 & 81 & 155 & 5.28 \\
\hline 8. & Diptera & Syrpidae* & 102 & 49 & 151 & 5.14 \\
\hline 9. & Homoptera & Cicadellidae & 77 & 56 & 133 & 4.53 \\
\hline 10. & Coleoptera & Coccinellidae & 62 & 64 & 126 & 4.29 \\
\hline 11. & Hymenoptera & Vespidae* & 45 & 64 & 109 & 3.71 \\
\hline 12. & Diptera & Asilidae & 24 & 55 & 79 & 2.69 \\
\hline 13. & Hemiptera & Nabidae & 42 & 24 & 66 & 2.25 \\
\hline 14. & Diptera & Tabanidae* & 35 & 27 & 62 & 2.11 \\
\hline 15. & Hymenoptera & Apidae* & 53 & 0 & 53 & 1.80 \\
\hline 16. & Diptera & Sarchopagidae* & 45 & 0 & 45 & 1.53 \\
\hline 17. & Diptera & Tipulidae & 40 & 0 & 40 & 1.36 \\
\hline 18. & Diptera & Tephritidae & 35 & 0 & 35 & 1.19 \\
\hline 19. & Diptera & Drosophilidae* & 27 & 0 & 27 & 0.92 \\
\hline 20. & Diptera & Muschidae* & 17 & 0 & 17 & 0.58 \\
\hline \multicolumn{3}{|c|}{ Lain-Lain } & 80 & 42 & 122 & 4.15 \\
\hline \multicolumn{3}{|c|}{ Jumlah } & 1650 & 1288 & 2938 & 100 \\
\hline
\end{tabular}

Keterangan :

(*) : Serangga Polinator

Kelimpahan famili serangga dengan jumlah individu yang tinggi dari beberapa famili menyebabkan adanya kodominansi pada habitat tersebut, famili serangga yang mendominasi pada saat musim berbunga dan berbuah adalah Dolichopodidae, Pompilidae dan Culicidae. Hal tersebut dapat dilihat dari nilai INP Dolichopodidae pada saat musim berbunga dengan nilai 15,24 dan 19,47 pada perkebunan apel. Wratten \& Van Emden, 1994; Wratten et al., 1998 juga disebutkan bahwa diversifikasi habitat dapat menyediakan nektar dan polen bagi parasitoid dan predator serta dapat berfungsi sebagai tempat berlindung sementara. 


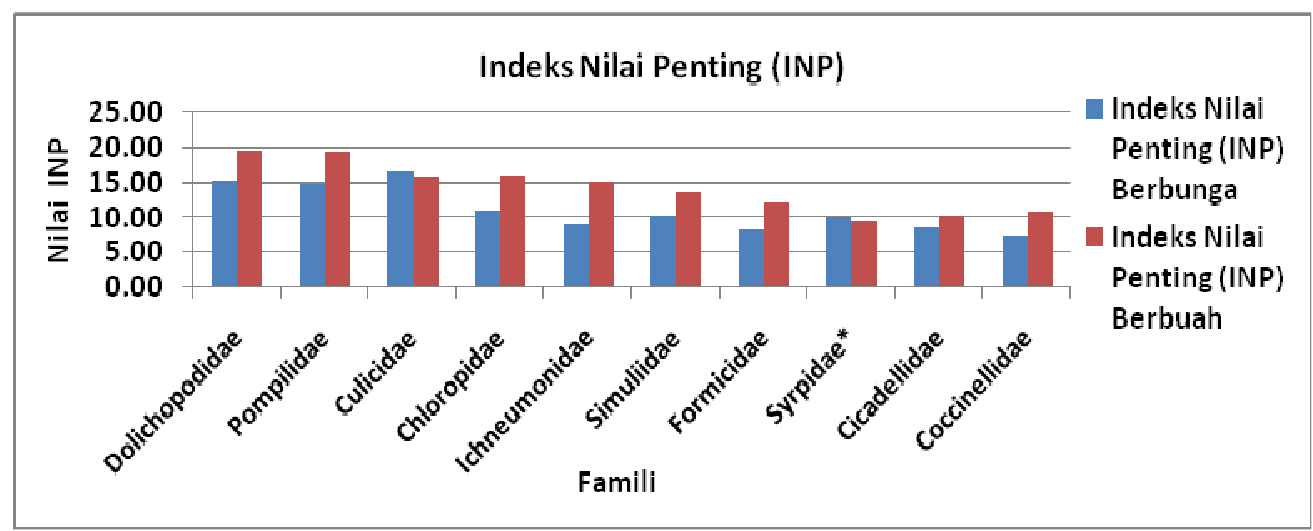

Gambar 1. Indeks Nilai Penting (INP) Serangga Saat Musim Berbunga Dan Berbuah, Pada Famili Yang Dominan

Analisis statistik kelimpahan serangga saat musim berbunga dan berbuah memiliki hasil yang signifikan dimana nilainya $\mathrm{P}<0,001$, sedangkan waktu pengambilan sampel antara musim berbunga dan berbuah juga memiliki hasil yang signifikan dengan nilai $\mathrm{P}=0,003$. Hal ini menunjukan bahwa antara musim dan waktu berpengaruh dalam kelimpahan serangga pada lahan perkebunan apel, sehingga terdapat perbedaan kelimpahan serangga antara musim berbunga dan berbuah dan waktu temporal. Kelimpahan serangga pada suatu habitat ditentukan oleh keanekaragaman dan kelimpahan pakan maupun sumberdaya lain yang tersedia pada habitat tersebut (Saragih, 2008). Faktor abiotik lingkungan seperti kelembaban, curah hujan, penyinaran, dan suhu juga dapat menyebabkan naik dan turunnya kelimpahan populasi.

Hasil perhitungan nilai indeks diversitas komunitas serangga saat musim berbunga sebesar 2,94 sedangkan saat musim berbuah sebesar 2,61. Hal ini menunjukan bahwa diversitas serangga pada saat musim berbunga dan berbuah di perkebunan apel termasuk kategori sedang atau medium $\left(\mathrm{H}^{\prime}>\right.$ 2-3). Kategori sedang pada kedua musim disebabkan karena aktivitas masyarakat dalam pengelolaan lahan pertanian yang kurang memperhatikan aspek lingkungan serta dipengaruhi oleh faktor lingkungan yang ada dan juga keragaman komponen yang menyusun ekosistem. Menurut Barbour et al. (1987) keanekaragaman jenis yang tinggi merupakan indikator dari kemantapan atau kestabilan suatu lingkungan pertumbuhan. Leksono (2007) menyatakan, semakin tinggi tingkat keanekaragaman, semakin kompleks interaksi yang mungkin terjadi antar spesies.
Analisis statistik keanekaragaman serangga saat musim berbunga dan berbuah memiliki hasil yang tidak signifikan dimana nilainya $\mathrm{P}=0,241$, sedangkan waktu pengambilan sampel antara musim berbunga dan berbuah memiliki hasil yang signifikan dengan nilai $\quad \mathrm{P}<0,001$. Hal ini menunjukan bahwa antara musim berbunga dan berbuah tidak berpengaruh dalam keanekaragaman serangga, sedangkan waktu berpengaruh dalam keanekaragaman serangga pada lahan perkebunan apel.

Tingkat kesamaan komposisi diversitas famili serangga pada saat musim berbunga dan berbuah berdasarkan hasil perhitungan Bray Curtis, kesamaan antara dua komposisi serangga pada saat musim berbunga dan berbuah adalah sebesar 0,79 , hal ini berarti komposisi serangga pada kebun apel saat musim berbunga dan berbuah $79 \%$ adalah sama (tidak berbeda), mendekati angka 1,0. Terdapat beberapa faktor yang menyebabkan tingginya tingkat kesamaan ini adalah antara lain ketersediaan makanan, mikro habitat, predator, tempat bersarang, dan intensitas gangguan.

\section{Komposisi Serangga Polinator Yang Berkunjung Pada Bunga Apel}

Total serangga polinator yang dikoleksi saat musim berbunga dan berbuah adalah sebesar 514 individu terdiri atas 3 ordo, 11 famili. Ordo serangga polinator dengan jumlah individu terbesar berasal dari ordo Diptera dengan jumlah 302 individu, Hymenoptera 162 individu, dan Lepidoptera 50 individu.

Kelimpahan serangga polinator saat musim berbunga dan berbuah memiliki jumlah yang berbeda. Kelimpahan serangga polinator 
saat berbunga lebih tinggi yaitu 363 individu terdiri atas 3 ordo, 11 famili sedangkan pada musim berbuah kelimpahan serangga polinator 151 individu terdiri atas 3 ordo, 5 famili. Serangga polinator saat musim berbunga meliputi famili Apidae dan Vespidae dari ordo Hymenoptera, Syrpidae, Sarchopagidae, Tabanidae, Drosophilidae, dan Muscidae dari ordo Diptera, Danaidae, Amatidae, Papilionidae, dan Pieridae dari ordo Lepidoptera. Serangga polinator saat musim berbuah meliputi famili Vespidae dari ordo Hymenoptera, famili Syrpidae, Tabanidae dari ordo Diptera, famili Danaidae dan Papilionidae dari ordo Lepidoptera.

Kelimpahan serangga polinator yang mengunjungi bunga apel pada hari pertama

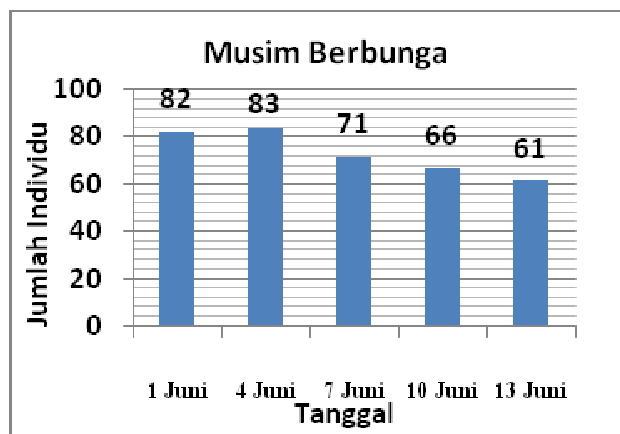

(A) sampai hari terakhir pengamatan saat musim berbunga mengalami penurunan jumlah serangga (Gambar 2), hal ini dikarenakan pada akhir pengamatan jumlah bunga pada tumbuhan apel sudah berkurang dan kalau diamati musim berbunga pada tanaman apel hanya berlangsung selama 12-14 hari. Serangga umumnya mengunjungi bunga karena adanya faktor penarik (attractant), yaitu bentuk bunga, warna bunga, serbuk sari dan nektar (sebagai penarik primer) dan aroma (sebagai penarik sekunder). Lebih dari $80 \%$ spesies tanaman tergantung oleh serangga untuk membawa serbuk sari dari bunga satu ke bunga lain (Raju \& Ezradanan 2002; Fahem et al. 2004).
Gambar 2. Pola Kunjungan Harian Serangga Polinator Berbunga

(A) Dan Berbuah (B) Pada Perkebunan Apel.
Analisis statistik kelimpahan serangga polinator saat musim berbunga dan buah memiliki hasil signifikan dengan nilai $\mathrm{P}<$ 0,001, sedangkan waktu pengambilan sampel antara musim berbunga dan berbuah juga memiliki hasil yang signifikan dengan nilai $\mathrm{P}<$ 0,001. Hal ini menunjukan bahwa antara musim dan waktu signifikan atau berpengaruh dalam kelimpahan serangga polinator. Kelimpahan serangga polinator pada saat musim berbunga dikarenakan adanya

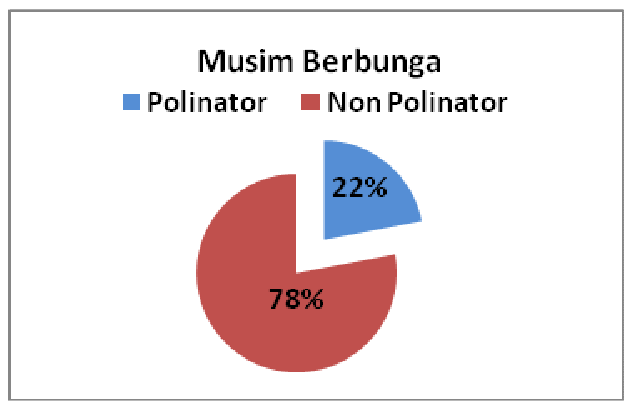

(A)

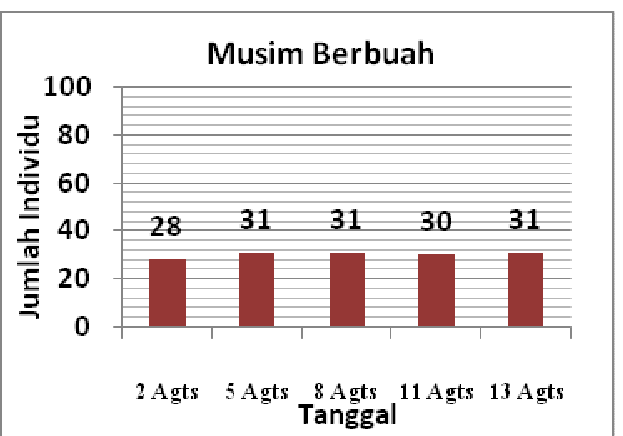

(B) kemelimpahan dan keanekaragaman jenis makanan yang tersedia bagi serangga pada saat itu, disamping itu juga karena adanya bentuk bunga, warna bunga, serbuksari, dan nektar (faktor primer), dan aroma (faktor sekunder).

Kunjungan serangga polinator yang mengunjungi bunga lebih tinggi jika dibandingkan dengan musim berbuah. Pada musim berbunga kelimpahan serangga polinator sebesar $22 \%$ sedangkan saat musim berbuah 12\%. (Gambar 3).

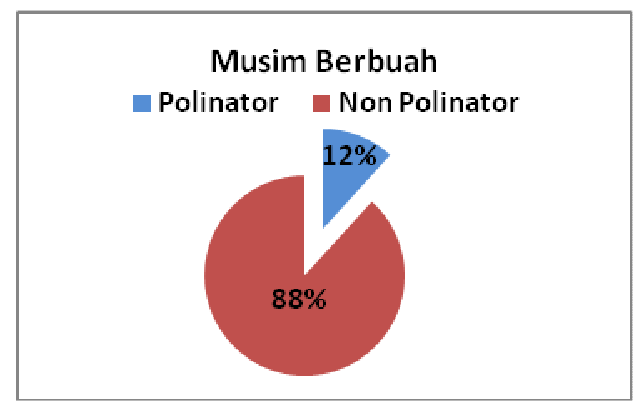

(B)

Gambar 3. Kelimpahan Serangga Polinator (A) Dan Non Polinator (B) 
Pada Saat Musim Berbunga Dan Berbuah.

Serangga secara umum mengunjungi bunga karena adanya faktor penarik yaitu bentuk bunga, warna bunga, serbuksari dan nektar (sebagai penarik primer) dan aroma (sebagai penarik sekunder), disamping itu pada musim bunga terdapat kelimpahan sumber makanan bagi serangga polinator ataupun tempat hidup bagi serangga tersebut. Ketika polinator mendapat banyak manfaat dari kontaknya dengan bunga, yang dapat berupa sumber makanan, tempat berlindung dan membangun sarang atau tempat melakukan perkawinan maka kontak tersebut dapat menjadi bagian yang tetap dalam hidupnya sehingga terbentuk interaksi yang konstan dengan tanaman tersebut (Griffin \& Sedgley, 1989).

Fase buah serangga polinator mengunjungi buah apel karena adanya nektar ekstrafloral yang dihasilkan oleh bagian tumbuhan selain bunga. Kandungan nektar sangat dipengaruhi oleh faktor lingkungan terutama kelembaban dan temperatur udara. Metcalf \& Metcalf (1992) mengatakan bahwa hampir seluruh daun, buah, dan bunga dari tumbuhan inang mengandung 30-80 tau lebih komponen senyawa volatil (senyawa yang mudah menguap) yang terdiri dari tipe dan struktur kimia yang sangat beragam. Serangga mampu merespon tumbuhan inangnya karena tingginya sensitivitas pada organ reseptor penciumannya.

Kelimpahan serangga polinator pada saat musim berbunga dikarenakan banyaknya keanekaragaman jenis makanan sehingga polinator dapat mencari alternatif makanan lainnya, karena makanan merupakan sumber gizi yang dipergunakan serangga untuk bertahan hidup dan melakukan perkembangbiakan. Krebs (2001), menyatakan bahwa pertumbuhan populasi organisme dipengaruhi oleh ketersediaan dan variabilitas sumber daya yang ada pada masing-masing habitatnya.

Pada perkebunan apel saat musim berbunga terdapat beberapa famili serangga polinator yang spesifik tidak ditemukan pada saat musim berbuah, yaitu dari famili Apidae (ordo Hymenoptera), Drosophilidae, Muscidae (ordo Diptera) dan famili Amatidae dan Pieridae (ordo Lepidoptera). Tidak hadirnya serangga polinator dari kelompok famili Apidae pada perkebunan apel saat musim berbuah dikarenakan, kelompok famili ini merupakan kelompok serangga penyerbuk yang efektif, dimana serangga ini merupakan jenis serangga yang efektif dalam membantu proses penyerbukan bagi tanaman. Lebah dari famili Apidae merupakan polinator yang berkoloni dan polinator yang mempunyai daya jelajah yang tinggi (Condit \& Enderud, 1956).

Famili Syrpidae dan Apidae merupakan jenis dari serangga penyerbuk yang efektif, famili Syrpidae merupakan salah satu jenis serangga yang dapat berperan ganda selain sebagai polinator serangga ini juga dapat berperan sebagai predator. Triplehorn \& Johnson (2005) menyatakan bahwa ada beberapa famili dari ordo Diptera yang berperan dalam penyerbukan adalah lalat-lalat bunga, salah satunya yaitu Syrpidae. Famili Vespidae merupakan jenis serangga tabuhan yang berperan sebagai polinator dan juga predator, kelimpahan serangga Vespidae tetap tinggi diduga karena jenis ini memiliki daya jelajah yang tinggi, dimana sepanjang hari imagonya aktif terbang dan mampu terbang cukup jauh (Ruppert, 1992). Chasanah (2010) dalam penelitiannya juga membuktikan bahwa lalat Diptera Tabanus sp (famili Tabanidae), Sarchopaga sp (famili Sarchopagidae) mengambil nektar sebagai sumber pakannya, dan keduanya mempunyai kelimpahan yang cukup tinggi pada $H$. multiflora dan dapat dikategorikan sebagai pengunjung dan berpotensi sebagai polinator. Penelitian pada tanaman kopi (C. arabica) yang diberi perlakuan kurungan dan non kurungan, ternyata yang berperan aktif dalam meningkatakan pembentukan buah dan biji adalah dari famili Drosophilidae (Atmowidi $e t$ al., 2007). Penelitian terhadap serangga penyerbuk tanaman jarak pagar di Karangploso, Malang yang juga berasal dari ordo Diptera (bangsa lalat buah) terdiri dari famili Sarchopagidae, Syrpidae, Muscidae (Asbani \& Winarno 2009). Serangga dari famili Apidae, Drosophilidae, Syrpidae dan Pieridae juga merupakan serangga polinator yang juga membantu penyerbukan hal ini dibuktikan bahwa serangga yang mengunjungi tanaman jarak pagar di Indramayu, Jawa barat adalah Hymenoptera, Lepidoptera, Diptera, Coeloptera, dan Thysanoptera (Atmowidi et al., 2008). Famili Pieridae dan Danaidae yang masuk dalam ordo Lepidoptera juga termasuk 
serangga polinator. Hal ini dibuktikan pada penelitian tentang tanaman jarak pagar $(J$. Curcas) dan Acalypha wilkesiana didominasi oleh tiga ordo, yaitu Hymenoptera, Diptera dan Lepidoptera (Atmowidi et al., 2007).

Kunjungan serangga pada tempo pertama dan kedua yakni jam (07.00-08.15) dan jam (09.00-10.15) didominasi oleh serangga dari golongan Syrpidae dan Apidae (Gambar 4). Hal ini dikarenakan serangga dari golongan Syrpidae dan Apidae merupakan jenis dari serangga penyerbuk yang efektif.

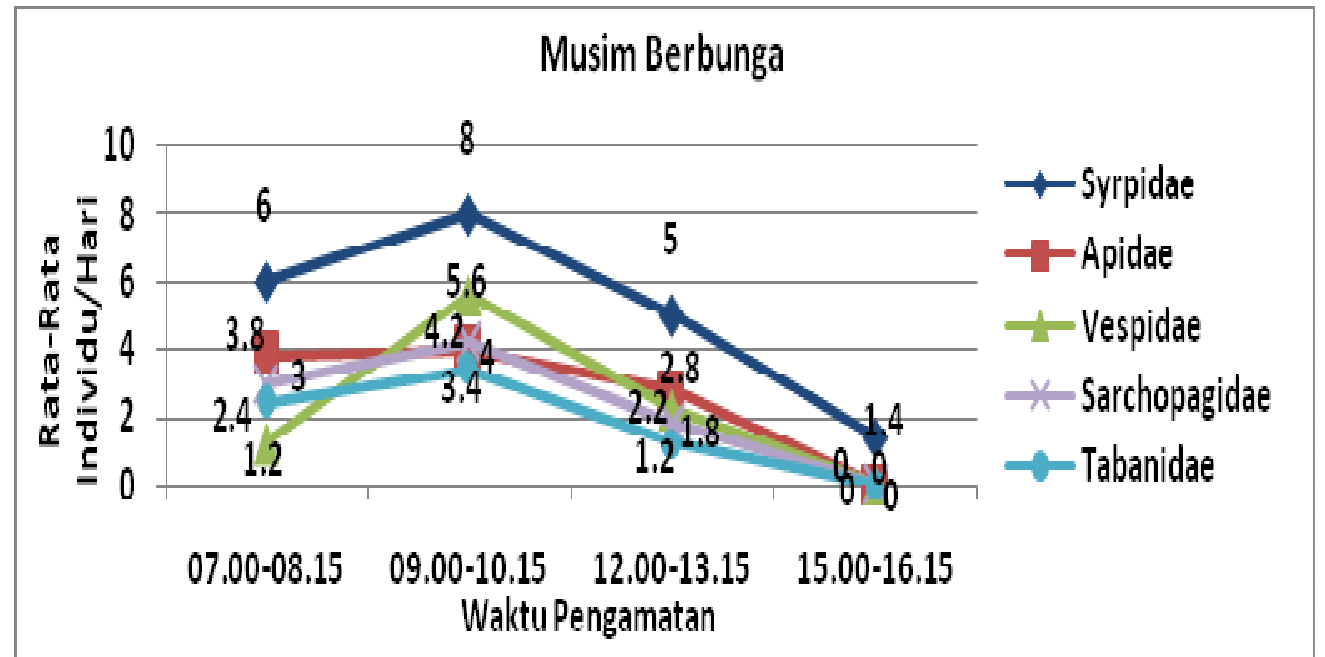

Gambar 4. Grafik Rata-Rata Kelimpahan Temporal Serangga Polinator Musim Bunga.

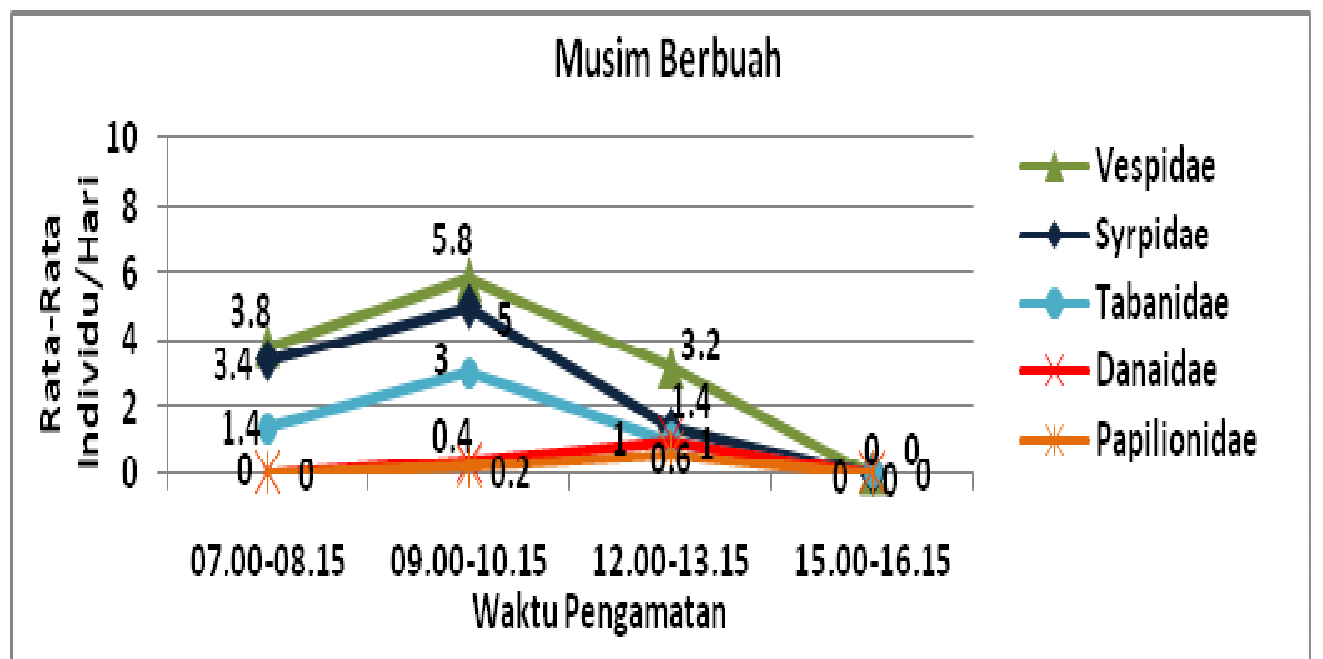

Gambar 5. Grafik Rata-Rata Kelimpahan Temporal Serangga Polinator Musim Buah.

Kelimpahan serangga Syrpidae pada musim berbunga mengalami kenaikan dari tempo pertama sampai kedua, kemudian menurun pada tempo ketiga sampai keempat, sedangkan kelimpahan Apidae pada musim berbunga mengalami kenaikan pada tempo pertama sampai kedua, kemudian mengalami penurunan pada tempo ke tiga dan ke empat. Hal ini dikarenakan kelimpahan serangga Syrpidae dan Apidae berperan efektif dalam membantu proses penyerbukan dan diduga serangga Syrpidae dan Apidae berkompetisi dalam mencari pakan. Kompetisi ini akhirnya dapat mendorong terjadinya perpindahan atau matinya sekelompok serangga (Jumar, 2000). Kompetisi terjadi akibat setiap spesies memerlukan makan, tempat hidup, cahaya, dan kebutuhan hidup lainnya yang sama.

Kelimpahan Syrpidae pada musim berbuah mengalami kenaikan pada tempo pertama sampai kedua, kemudian mengalami penurunan pada tempo ketiga sampai keempat, 
sedangkan Vespidae mengalami kenaikan pada tempo pertama sampai kedua dan mengalami penurunan pada tempo ketiga sampai keempat (Gambar 5). Hal ini dikarenakan serangga mempunyai mekanisme secara fisiologis untuk mengukur waktu aktifitasnya, yang dikenal sebagai jam biologi. Secara umum jam biologi harian adalah kemampuan serangga untuk menentukan waktu bagi serangga, kapan untuk melakukan aktivitas dan kapan waktu untuk serangga beristirahat. Jam biologi juga dikaitkan dengan periodisitas yang berhubungan dengan bulan dan daur musim.

Pada tempo ketiga (12.00-13.15)

terlihat kelimpahan serangga polinator mengalami penurunan, hal ini disebabkan karena adanya ketidaksesuaian iklim mikro atau suhu pada lingkungan tersebut. Serangga memiliki kisaran suhu tertentu dimana dia dapat bertahan hidup. Di luar kisaran suhu tersebut serangga akan mati kedinginan atau kepanasan. Pengaruh suhu ini jelas terlihat pada proses fisiologi serangga. Pada suhu tertentu aktifitas serangga tinggi, akan tetapi pada suhu lain akan berkurang atau menurun. Pada umumnya kisaran suhu efektif adalah : suhu minimum $15^{\circ} \mathrm{C}$, suhu optimum $25^{\circ} \mathrm{C}$, dan suhu maksimum $45^{\circ} \mathrm{C}$ (Jumar, 2000). Serangga merupakan organisme yang bersifat poikiloterm, sehingga suhu badan serangga banyak dipengaruhi oleh suhu lingkungan. Pada tempo keempat (15.00-16.15) menunjukan bertambahnya kelimpahan dari serangga polinator tertentu meskipun jumlah penambahannya tidak sebanyak tempo sebelumnya, hal ini dikarenakan beberapa aktivitas dari serangga di pengaruhi oleh respon terhadap cahaya yang berperan dalam proses pertumbuhan, perkembangan dan kelangsungan hidup dari serangga tersebut.

Hasil perhitungan nilai indeks diversitas komunitas serangga polinator saat musim berbunga sebesar 2,08 sedangkan nilai indeks diversitas pada saat musim berbuah sebesar 1,27. Hal ini menunjukan bahwa diversitas serangga pada saat musim berbunga dan berbuah di perkebunan apel termasuk kategori rendah (H'>1-2). Kategori rendah pada kedua musim di perkebunan apel ini disebabkan karena aktivitas masyarakat dalam pengelolaan lahan pertanian yang kurang memperhatikan aspek lingkungan serta dipengaruhi oleh faktor lingkungan yang ada dan juga keragaman komponen yang menyusun ekosistem. Menurut Krebs (2001) keanekaragaman jenis untuk mengukur tingkat keteraturan dan kestabilan suatu ekosistem hal ini diartikan bahwa semakin rendah nilai indeks keanekaragaman maka semakin menurun tingkat keteraturan dan kestabilan ekosistem.

Analisis statistik keanekaragaman serangga polinator saat musim berbunga dan berbuah memiliki hasil yang signifikan dimana nilainya $\mathrm{P}<0,001$, waktu pengambilan sampel antara musim berbunga dan berbuah juga memiliki hasil yang signifikan dengan nilai $\mathrm{P}<0,001$. Hal ini menunjukan bahwa antara musim berbunga dan berbuah dan waktu berpengaruh dalam keanekaragaman serangga polinator. Keanekaragaman serangga polinator di suatu habitat dipengaruhi oleh ketersediaan sumber pakan dan faktor lingkungan. Beberapa serangga pengunjung dapat dikategorikan sebagai serangga penyerbuk, yaitu dari ordo Hymenoptera, Diptera dan Lepidoptera (Banjo et all, 2006).

Individu tertinggi dan dominan pada perkebunan apel pada saat musim berbunga adalah famili Syrpidae dari ordo Diptera dengan nilai INP sebesar 39,21 dengan kelimpahan relatif $28,09 \%$, sedangkan pada musim berbuah didominasi oleh famili Vespidae dengan nilai INP sebesar 65,11 dengan kelimpahan relatif $42,38 \%$. Syrpidae disamping bersifat sebagai polinator juga sebagai predator dan dapat bergerak aktif sehingga mampu bertahan hidup dan berkembangbiak sehingga keberadaannya mampu mendominasi suatu komunitas, selain itu hewan ini mampu menghasilkan telur dalam jumlah banyak.

Tingkat kesamaan antar komunitas tiap periode waktu dapat dianalisis dengan menggunakan indeks Bray Curtis. Hasil perhitungan indeks kesamaan Bray Curtis berdasarkan kelompok musim berbunga dan berbuah disajikan pada (Tabel 2). 
Tabel 2. Matriks Nilai Indeks Kesamaan Bray Curtis di Kelompok Musim Bunga Dan Musim Buah

\begin{tabular}{lllll}
\hline Musim Bunga & $07.00-08.15(\mathrm{~A})$ & $09.00-10.15(\mathrm{~B})$ & $12.00-13.15(\mathrm{C})$ & $15.00-16.15(\mathrm{D})$ \\
\hline $07.00-08.15(\mathrm{~A})$ & & 0,69 & 0,76 & 0,13 \\
\hline $09.00-10.15(\mathrm{~B})$ & & & 0,64 & 0,07 \\
\hline $12.00-13.15(\mathrm{C})$ & & & & 0,15 \\
\hline $15.00-16.15(\mathrm{D})$ & & & \\
\hline \multicolumn{7}{l}{ Musim Buah } & $07.00-08.15(\mathrm{~A})$ & $09.00-10.15(\mathrm{~B})$ & $12.00-13.15(\mathrm{C})$ & $15.00-16.15(\mathrm{D})$ \\
\hline $07.00-08.15(\mathrm{~A})$ & & 0,74 & 0,27 & 0,50 \\
\hline $09.00-10.15(\mathrm{~B})$ & & 0,57 & 0,00 \\
\hline $12.00-13.15(\mathrm{C})$ & & & 0,00 \\
\hline $15.00-16.15(\mathrm{D})$ & & & \\
\hline
\end{tabular}

Indeks Bray Curtis mendeskripsikan bahwa pada saat musim berbunga dalam periode waktu yang menunjukan tingkat kesamaan tertinggi adalah AC (07.00-08.15 dengan 12.00-13.15) dengan nilai 0,76 dan pada musim berbuah adalah $\mathrm{AB}(07.00-08.15$ dengan 09.00-10.15) dengan nilai 0,74. Terdapat beberapa faktor yang menyebabkan tingginya tingkat kesamaan ini adalah antara lain aktivitas kunjungan serangga umumnya pada pagi sampai siang hari tinggi dan aktivitas di sore hari semakin menurun, ketersediaan makanan, mikro habitat, predator, tempat bersarang, dan intensitas gangguan sehingga jumlah komposisi dan variasi jenis serangga polinator yang ada pada dua waktu tersebut sama. Pada saat musim berbunga AC (07.00-08.15 dengan 12.00-13.15) jumlah individu yang ditemukan adalah 94 dan 84, kesamaan individu yang ditemukan adalah 76\%. Proporsi kesamaan jenis antara kedua waktu tersebut lebih besar dibandingkan dengan waktu yang lain. Selain itu indeks keragaman kedua waktu tersebut tidak jauh berbeda. Pada saat musim berbuah AB (07.0008.15 dengan 09.00-10.15) jumlah individu yang ditemukan adalah 43 dan 72, kesamaan individu yang ditemukan adalah $74 \%$. Proporsi kesamaan jenis antara kedua waktu tersebut lebih besar dibandingkan dengan waktu yang lain. Selain itu indeks keragaman kedua waktu tersebut tidak jauh berbeda.

Hubungan Kelimpahan dan Diversitas Serangga Dengan Faktor Lingkungan.

Faktor lingkungan yang diamati pada penelitian ini adalah suhu udara $\left({ }^{0} \mathrm{C}\right)$, kelembaban udara dan intensitas cahaya (Lux). Berikut adalah hasil pengamatan suhu, kelembaban dan intensitas cahaya pada lokasi penelitian (Gambar 6, 7, dan 8).

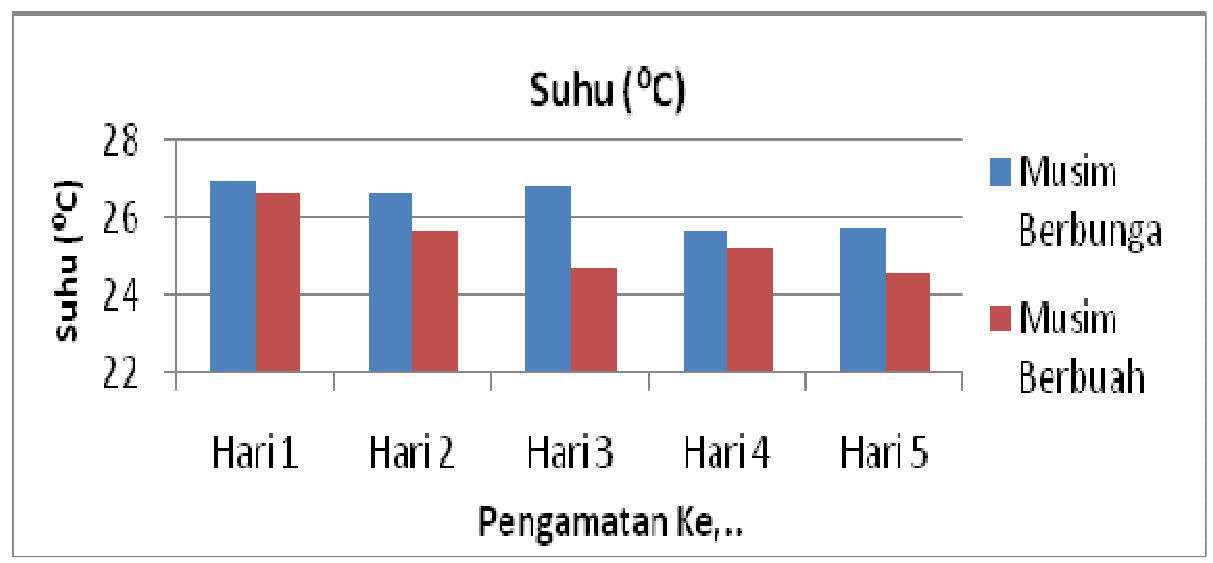

Gambar 6. Perbandingan Rata-Rata Suhu Udara $\left({ }^{\circ} \mathrm{C}\right)$

Saat Musim Berbunga Dan Berbuah 


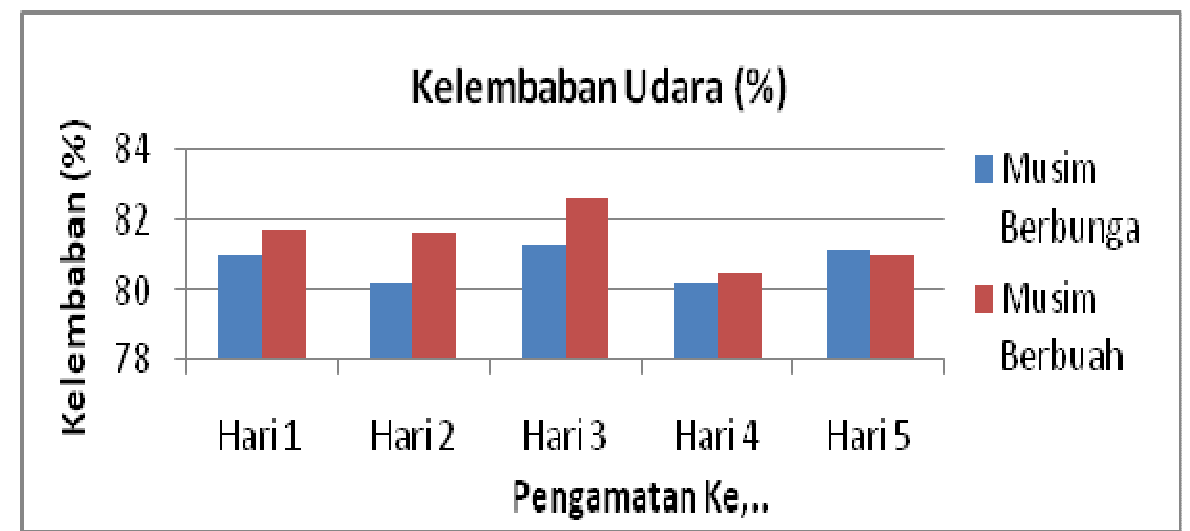

Gambar 7. Perbandingan Rata-Rata Kelembaban Udara

Saat Musim Berbunga Dan Berbuah.

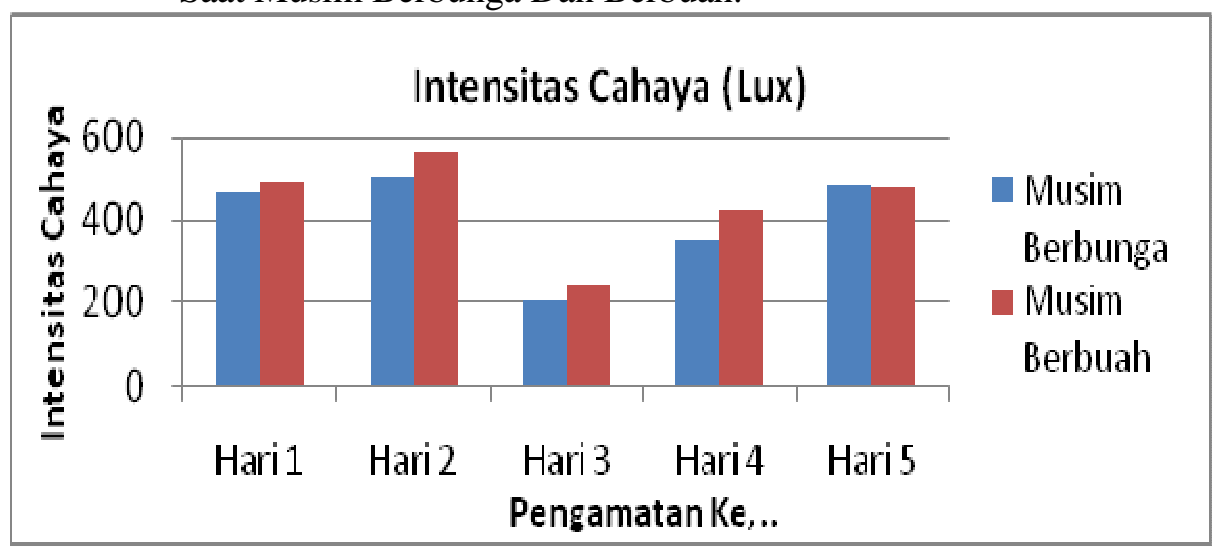

Gambar 8. Perbandingan Rata-Rata Intensitas Cahaya

(Lux) Saat Musim Berbunga Dan Berbuah.

Suhu merupakan salah satu faktor abiotik yang menentukan keanekaragaman dan kelimpahan serangga pada perkebunan apel. Hasil pengukuran faktor lingkungan dilakukan kompilasi untuk mendapatkan hubungan korelasi antara faktor lingkungan dengan kelimpahan serangga. Analisis dilakukan dengan Regresi, hasil pengujiannya disajikan pada. Nilai Adjusted R-Square sebesar 0,432 atau 43,2\% kelimpahan dari serangga dipengaruhi oleh suhu, cahaya dan kelembaban, sedangkan sisanya $56,8 \%$ di pengaruhi oleh faktor lain. Sehingga didapatkan korelasi antara kelimpahan serangga dengan faktor lingkungan, dimana korelasi antara faktor lingkungan dengan kelimpahan serangga rendah. Berdasarkan persamaan regresi dengan uji koefisien dapat diketahui bahwa faktor suhu pada saat musim bunga berkorelasi positif terhadap kelimpahan serangga polinator dengan nilai koefisien 20,142. Sedangkan faktor cahaya dan kelembaban berkorelasi negatif, sehingga berpengaruh menurunkan kelimpahan serangga polinator. Pada musim buah kelimpahan serangga dari setiap temporal mengalami penurunan, karena pada musim buah rata-rata suhu lebih rendah sedangkan cahaya dan kelembaban rata-rata lebih tinggi daripada musim bunga, sehingga berpengaruh terhadap kelimpahan serangga.

Serangga polinator dalam membantu proses penyerbukan pada tumbuhan apel terkait dengan kondisi lingkungan yang berada disekitar kebun apel. Suhu udara, intensitas cahaya dan kelembaban udara merupakan faktor penting untuk mempengaruhi aktivitas dan perkembangan serangga, dimana serangga memiliki kisaran suhu udara tertentu untuk hidup. Jumar (2000) menyatakan bahwa kisaran suhu efektif untuk serangga dalam perkembangan hidup adalah antara $15-45^{\circ} \mathrm{C}$. Dengan kisaran suhu optimum untuk berkembangbiak adalah suhu $25{ }^{\circ} \mathrm{C}$. Serangga juga membutuhkan kadar air dalam udara atau kelembaban tertentu untuk beraktifitas. Kelembaban yang tinggi berpengaruh pada distribusi, kegiatan, dan perkembangan serangga. Pada kelembaban yang sesuai serangga lebih toleran terhadap suhu ekstrim (Jumar, 2000). Intensitas cahaya merupakan banyaknya cahaya matahari yang dapat 
berpengaruh terhadap kehidupan organisme khususnya serangga. Cahaya matahari dibutuhkan secara tidak langsung oleh hewan, akan tetapi sinar matahari dapat dimanfaatkan sebagai suatu penanda akan aktifitas tertentu. Serangga memanfaatkan sinar matahari untuk proses mencari makan, molting, reproduksi atau peristiwa yang terkait sejarah hidupnya (Leksono, 2007). Cahaya mempengaruhi distribusi lokal suatu serangga, sehingga serangga tersebut dapat beraktifitas sesuai dengan respon sinyal yang berasal dari sinar matahari. Beberapa serangga adalah bersifat diurnal, dimana akan beraktifitas pada saat terdapat cahaya matahari dan bersifat nokturnal, dimana akan beraktifitas pada malam hari (Jumar, 2000).

Faktor lingkungan antara musim bunga dan musim buah tidak menunjukkan perbedaan yang jauh antara suhu, kelembaban, dan intensitas cahaya namun kelimpahan dan keanekaragaman serangga polinator yang berkunjung pada musim bunga dan musim buah berbeda, hal ini dikarenakan pada musim bunga serangga polinator datang disamping mencari makanan juga membantu penyerbukan, sedangkan pada musim buah kunjungan dan kelimpahan serangga polinator menurun.

\section{Kesimpulan}

1. Keanekaragaman famili serangga pada kebun apel pada saat musim berbunga terdapat 35 famili dan pada saat musim berbuah terdapat 21 famili. Nilai indeks diversitas pada saat musim berbunga sebesar $(2,94)$ sedangkan angka indeks diversitas untuk musim berbuah sebesar 2,61 .

2. Variasi harian dan musiman serangga polinator pada musim bunga dan buah menunjukan perbedaan kelimpahan, pada musim bunga kelimpahan serangga polinator lebih tinggi dari pada musim buah, pada saat musim bunga kelimpahan serangga polinator $22 \%$ sedangkan pada saat musim buah hanya $12 \%$.

3. Komposisi komunitas serangga polinator yang mengunjungi pohon apel meliputi 3 ordo 11 famili. Serangga polinator yang mengunjungi bunga didominasi dari famili Syrpidae dari ordo Diptera dengan kelimpahan relatif 28,09 dan famili Apidae dari ordo Hymenoptera dengan kelimpahan
14,60. Nilai indeks diversitas pada saat musim berbunga sebesar 2,08.

\section{Daftar Pustaka}

Amano K, Nemoto T, Heard TA. 2000. What are Stingless Bees and Why and How to use Them as Crop Pollinator. A Review JARRQ. 34:183-190

Atmowidi, T., Rianti P., Sutrisna A. 2008. Pollination Effectivenes of Apis cerana Fabricus and Apis melifera Linnaeus in Jatropha curcas L. (Euphorbiaceae). Biotropika 15:28134.

Banjo, A.D., Lawal O.A., Aina, S.A. 2006. The Entomofauna of two medicinal Euphorbiaceae in Southwestern Nigeria. J. Appli. Sci. Res. 2:858863.

Barth FG. 1991. Insect and Flowers. The Biology ang Partnership. New Jersey: Princeton University Press.

Barbour, M.G., Triplehorn,C.A., \& W.D.Pitts. 1987. Terrestrial Plant Ecology. Chapter 9: Method of Sampling The Plant Community. Menlo Park, Benjamin/Cummings Publishing Co. CA.

Borror, D.J., C.A. Triplehorn, dan N. F. Johnson, 1998. Pengenalan Pelajaran Serangga Edisi keenam. Gadjah Mada University Press. Jogyakarta.

Chasanah, Lilih R. 2010. Keanekaragaman dan Frekuensi Kunjungan Serangga Penyerbuk Serta Efektivitasnya Dalam Pembentukan Buah Hoya multiflora Blume (Asclepiadaceae). Institut Pertanian Bogor. Bogor.

Condit \& Enderud. 1956. Dalam Tree Fruits \& Nuts abd Exotic Tree Fruits \& Nuts. http://bee.airoot com/ beeculture/chap 5/fig.htm diakses 3 Maret 2012.

Eka Putra, R. 2006 .Polinasi: Servis Alam Yang Terabaikan http://www.google.com, diakses tanggal 20 Agustus 2011

Erna, Faridhatul U. 2011. Antraktifitas dari Tegetes erecta L, Bidens Pilosa L, Mimosa pudica L, Cyperus rotundus L, Terhadap Arthropoda Padi di Lahan Pertanian Pakis 
Malang. Tesis Universitas

Brawijaya. Malang

Faheem M, Aslam M, \& Razaq M. 2004. Pollination Ecology With Special Reference to Insect a Review. J. Res, Sci. 4:395-409

Griffin, A.R., \& Sedgley, M. 1989. Sexsual Reproduction of Tree Crops. Academic Press Inc. Harcourt Brace Jovanovich Publisher. San Diego.

Jumar. 2000. Entomologi Pertanian. Jakarta: Rineka Cipta.

Kearns CA, Inouye DW. 1997. Pollinator, Flowering Plants and Consevation Biology. Bio Sci. 47:297-307

Kevan, P.G. and T.P. Phillips. 2001. The Economic Impact Of Polinator Declines: An Approach to Assesing the Consequences. Conservation Ecology 5(1):8

Krebs, C.J. 2001. Ecology: The Experimental Analysis of Distribution and Abudance. 5th ed. Benjamin Cummings. Menlo Park, California.

Leksono, S. 2007. Ekologi Pendekatan Deskriptif dan Kuantitatif. Bayu Media. Malang

Magguran, A. E. 1998. Ecological Divercity and Its Measurement. Princeton UP. Princeton.

Metcalf, R.L., \& W.P. Metcalf. 1992. Plant Kairomones in Insect Ecology and Control. Chapman and Hall. New York, Page 9.

Nur Asbani, Dwi Winarno. 2009. Bioekologi Penyerbukan Dan Pembuahan Pada Jarak Pagar Andromonoecious. Balai Penelitian Tanaman Tembakau Dan Serat. Malang.

Raju AJS, Ezradanam V. 2002. Pollination ecology and fruiting behavior in a monoecious species, Jatropha curcas L. (Euphorbiaceae). Cur. Science. 83: 1395-1398.

Ruppert, V. 1992. Einfluss Blutenreicher Feldranstrukturen af Die Dichte Bluten Beruschender Nutzinsekten Insbesondere der Syrpinae (Diptera:Syrpidae Agrarokologie. Bert. Stuttgart.

Saragih, A. 2008. Indeks Keanekaragaman Jenis Serangga Pada Tanaman Stroberi (Fragaria sp.) di
Lapangan. Skripsi. Jurusan Ilmu Hama dan Penyakit Tumbuhan. Fakultas Pertanian. Universitas Sumatera Utara. Medan.

Triplehorn, C.A., \& Johnson, N.F. 2005. An Introduction to The Study of Insects. Philadelfia: WB.Saunders.

Wratten dan Van Emden, 1994; Wratten et al., 1998. Habitat Managemen for Echanched Activity of Natural Enemies of Insect Pests. In D. M. Glen, M. P. Graves and H. M. Anderson. Ecology and Integrated Farming System Chilchester. UK. Willey. P. 117-146. 